\title{
Los primeros japoneses en Guadalajara
}

DOI: $10.32870 /$ mycp.v3i7.459

Melba Falck Reyes ${ }^{1}$

Héctor Palacios ${ }^{2}$

\section{Resumen}

Con la llegada de los españoles al Océano Pacífico a través de la Nueva España y la subsecuente colonización de las Filipinas, ocurrieron los primeros contactos entre el mundo novohispano y Japón, donde destacan al menos un par de embajadas oficiales de cada lado. Dentro de este marco nos encontramos con la historia de un par de personajes japoneses que llegaron a ocupar un lugar protagónico en la sociedad de la Guadalajara del siglo XVII. Sus nombres: Luis de Encío y Juan de Páez. Del primero se cree que antes de arribar a la Nueva Galicia tuvo una vida como samurai. Sobre Juan de Páez descubrimos que nació en la ciudad de Osaka, aunque aún está pendiente saber cómo llegó a Guadalajara. Encío alcanzó a destacarse como mercader de esta ciudad, mientras que Páez fue de los hombres más adinerados e influyentes de la región. Con este texto ofrecemos un resumen de la historia de estos dos japoneses convertidos en tapatíos, la cual embona como una pieza más en la historia de las relaciones entre Asia y América a través del Pacífico.

Palabras clave: relaciones transpacíficas, historia, migración japonesa, Nueva España, Japón.

Artículo recibido el 12 de febrero de 2014 y dictaminado el 03 de marzo de 2014.

1. Doctora en Relaciones Internacionales por la Universidad de Colima. Profesora-investigadora del Departamento de Estudios del Pacífico del cucsh, Universidad de Guadalajara. Miembro del SNI. ORCID http://orcid.org/0000-0003-4926-0594 Correo electrónico: mefalck@gmail.com

2. Investigador independiente. Licenciado en Historia por la Universidad de Guadalajara. Correo electrónico: hpalacios_m@yahoo.com.mx 


\section{Abstract}

With the Spaniard's arriving to the Pacific Ocean through New Spain and the subsequent colonization of Philippines, the first contacts happen between people form New Spain and Japan, where we can point at least two diplomatic missions from each part. Inside that context, there is the history of a couple of Japanese men who became to get an important place in Seventeenth Century Guadalajara's society. Their names: Luis de Encío and Juan de Páez. Maybe the first one was a samurai before he arrived to Nueva Galicia. About Juan de Páez we discovered that he was born in Osaka city, although it is on schedule find out how he came to Guadalajara. Encío was a prominent merchant during some years in this city; at the time, Páez was one of the richest and important men on the region. This article gives a summary of the history of this two Japanese who became tapatios, a history that could take part in the one that tells the relationships between Asia and America through the Pacific Rim.

Keywords: transpacific relations, history, Japanese migration, New Spain, Japan.

El historiador francés Thomas Calvo, especialista en el estudio de la Guadalajara colonial, publicó en 1983 un artículo en la Revista de Indias (España) que trataba sobre unos japoneses que vivieron en la Guadalajara del siglo XVII. En ese artículo hablaba principalmente de dos personajes: Luis de Encío y Juan de Páez (éstos eran sus nombres conversos). El texto en cuestión fue a dar a las manos del entonces embajador de Japón en España, Eikichi Hayashiya, quien había estado previamente en México como agregado cultural de la embajada de su país. De los hallazgos de Calvo, el que llamó poderosamente la atención de Hayashiya fue el de la firma en caracteres japoneses que uno de los nipones había dejado estampada en un documento de la época.

Al regresar a Japón, Hayashiya hizo examinar esa firma. Ésta, en letras ideográficas kanji, representaba el nombre japonés de este personaje: Fukuchi Soemon o Hyoemon, y en letras fonéticas hiragana indicaba su nombre castellano: Luis de Encío. Con esa información Hayashiya comenzó a seguir la pista a Fukuchi y en sus investigaciones llegó a la conclusión de que éste probablemente provenía del poblado del mismo nombre: Fukuchi, cercano a la ciudad de Sendai, al norte de la actual Tokio. Este hallazgo de Hayashiya era importante para determinar cómo había llegado Fukuchi a la Nueva España, 
ya que desde Sendai partió en 1613 la famosa Misión Hasekura enviada por el daimyô de Sendai, Date Masamune.

En 2002, Hayashiya viajó a Guadalajara para presentar en la Universidad de Guadalajara la conferencia: "Los japoneses que se quedaron en México en el siglo XVII. Acerca de un samurai en Guadalajara”. Ése fue nuestro primer encuentro con estos japoneses. Cuatro años más tarde comenzamos una investigación formal sobre los dos japoneses más destacados del grupo encontrado por Calvo: Luis de Encío y Juan de Páez. Nuestro objetivo con ese proyecto era rescatar, con la ayuda de un examen minucioso de los documentos históricos de la época y por supuesto, con el apoyo del trabajo seminal de Calvo, la historia de esos dos nipones en la Guadalajara colonial. A tres años de iniciado ese proceso, publicamos los resultados de nuestra investigación en el libro El japonés que conquistó Guadalajara. La historia de Juan de Páez en la Guadalajara del siglo XVII.

El trabajo que aquí presentamos es un extracto de ese libro, en el que destacamos el papel que como mercaderes desempeñaron Páez y Encío en Guadalajara. Aunque no aportamos nuevos hallazgos, nuestro objetivo es aprovechar la oportunidad que nos brinda la conmemoración del 400 aniversario de la Misión Hasekura, que pasó por la Nueva España en 1614, para continuar difundiendo esta historia entre un público más amplio e interesar a otros investigadores en los estudios sobre la influencia asiática en América. Esto sin contar con que México y la Cuenca del Pacífico nos brinda la oportunidad, con la versión digital, de alcanzar una audiencia más amplia en contraste con el limitado tiraje del libro.

El artículo está dividido en cuatro apartados. En una primera sección damos una mirada al entorno en el que se dieron los primeros contactos entre los novohispanos y los japoneses; ésta es seguida por un segundo apartado en el que presentamos nuestras hipótesis sobre cómo podrían haber llegado estos japoneses a Guadalajara, y que continúan siendo hipótesis, pues todavía no hemos podido comprobarlas con base en los documentos consultados. En la tercera y cuarta sección abordamos, por separado, el papel desempeñado por Luis de Encío y Juan de Páez en su carácter de mercader el primero, y de hombre de negocios y financiero el segundo. Dicho texto concluye con un repaso de nuestros hallazgos y pendientes sobre el tema. 


\section{Los primeros contactos novohispanos con Asia}

Para nosotros, esta historia comienza con los primeros contactos de España con Asia, los cuales se dieron a través de la Nueva España (hoy México) en el siglo XVI. En 1527, por orden de Carlos I, el conquistador Hernán Cortés envió a Álvaro de Saavedra Cerón a explorar el Océano Pacífico; éste salió del puerto de Zihuatanejo, hoy convertido en un bello destino turístico del Pacífico mexicano, y llegó tres meses después al archipiélago que los españoles bautizaron con el nombre de Filipinas. Varias misiones siguieron a ésta pero ninguna de ellas había podido encontrar una ruta de regreso a la Nueva España. Fue hasta 1564, en el viaje transpacífico encabezado por Miguel López de Legaspi y el fraile vasco Andrés de Urdaneta (quien contaba con una gran experiencia en expediciones previas en el Pacífico) que esta ruta fue descubierta.

Legaspi y Urdaneta habían salido del Puerto de Navidad (al suroeste del actual estado de Jalisco), arribaron a las Filipinas en febrero de 1565; a mediados de ese año Urdaneta encontró la ruta de regreso al dirigirse rumbo al norte, al archipiélago japonés, y a partir de allí seguiría la corriente Siwo que lo llevaría a las costas californianas, y costeando, llegaría a Acapulco. Legaspi, por su parte, permaneció en las Filipinas, fundó Manila como la capital del archipiélago en 1571 y se convirtió en su primer gobernador. A partir de entonces fue frecuente la llegada de embarcaciones chinas a Manila con el objeto de establecer comercio con los españoles. En 1573 arribó formalmente la primera remesa de artículos chinos a Acapulco, no sin antes atracar en el Puerto de Navidad (Calderón, 1988: 565; Molina, 1992: 102 y 103). Este comercio transpacífico influyó sobre las relaciones con Japón, ya que ese país se convertiría en un eventual proveedor del Galeón y en una escala necesaria para el largo viaje de regreso a través del gran Océano Pacífico.

Fue en la última década del siglo XVI cuando se establecieron los primeros acercamientos diplomáticos entre hispanos y japoneses. ${ }^{3} \mathrm{El}$ primero fue en 1592, cuando Toyotomi Hideyoshi (uno de los tres unificadores del Japón junto con Oda Nobunaga y Ieyasu Tokugawa), envió una embajada a Manila para exigir a los hispanos convertirse en sus tributarios. El entonces gobernador español en Filipinas, Gómez Pérez Dasmariñas supo hacer un buen

3. Sin contar la "Embajada de los Jóvenes", formada por cuatro japoneses adolescentes miembros de la nobleza feudal de la isla de Kiushu, y que en 1584 arribaron a Europa guiados por religiosos jesuitas (véase: Judith Brown y Adriana Boscaro). 
manejo diplomático de la situación, y logró apaciguar hasta cierto punto el tono amenazante de Hideyoshi.

Durante los siguientes 17 años continuó un intercambio diplomático intermitente entre Japón y Manila con sus respectivos altibajos, pero en general sin lograr avances sustanciales en la relación. Los intereses de una y otra parte eran distintos: mientras a Japón le interesaba el tema del intercambio comercial, sabiendo ya la importancia del comercio de mercancías asiáticas que se transportaban de Manila a la Nueva España, para la parte hispana la evangelización cristiana era el objetivo primordial.

La cristianización de Japón había comenzado en 1549 con el arribo del jesuita Francisco Javier a Japón, y durante más de 40 años los jesuitas fueron la única orden cristiana en aquellas tierras, quienes enfocaron sus tareas evangelizadoras principalmente en las élites feudales del archipiélago nipón (Boxer, 1951). Fue en la década de 1590 cuando arribaron los primeros franciscanos, cuya actitud contradictoria respecto a la autoridad central japonesa conllevó a la primera ejecución de católicos en Japón en el puerto de Nagasaki; esto fue en el año de 1597, y prácticamente todos los ejecutados fueron franciscanos, con excepción de tres japoneses conversos por jesuitas.

No obstante, en 1598, después de la muerte de Hideyoshi, la inestabilidad política interna por el control del poder, combinada con el apoyo de poderosos daimyô a las misiones católicas, sirvieron para propagar notoriamente el cristianismo en Japón. Los jesuitas supieron aprovechar esta situación incrementando su número de residencias de cuatro a 30 entre 1599 y 1600 , registrándose en ese lapso, de acuerdo con fuentes jesuitas, 70,000 conversiones. ${ }^{4}$

El inicio del nuevo siglo atestiguó el triunfo de Ieyasu Tokugawa y aunque éste no veía con buenos ojos la labor evangelizadora de los misioneros, éstos vivieron un periodo de aparente calma para realizar sus cometidos de evangelización, arribando incluso otras órdenes religiosas como los dominicos y los agustinos. Sin embargo, razones políticas conducirían a que en 1612 el gobierno japonés mandara cerrar las iglesias cristianas y a quitarle a los misioneros sus propiedades y residencias. Para 1613 se emitió un edicto que decretaba la expulsión de los religiosos (Borao, 2005: 13), el cual entró en vigor en 1614, iniciando una erradicación sistemática del cristianismo en Japón.

4. De acuerdo con Joao Paulo Oliveira e Costa, en 1600 habría en Japón alrededor de 300 mil japoneses que profesaban la religión católica, muchos de ellos nobles, y de los cuales al menos 14 daimyó habían sido bautizados (Oliveira e Costa, 2003: 56). 
Es importante que hablemos aquí sobre la comunidad japonesa que se estableció en Manila. A partir de 1585 empezaron a llegar embarcaciones japonesas a ese puerto con fines comerciales. Muchos de los japoneses que viajaban en esos barcos comenzaron a quedarse en Manila, conformando poco a poco una comunidad más o menos numerosa, sumándoseles otros japoneses que ya habitaban en otras partes de Filipinas y que por diversas razones se movieron a la capital.

Con el transcurso de los años la colonia japonesa fue aumentando paulatinamente, aunque con algunos lapsos de decrecimiento, como sucedió en 1597, cuando a raíz del martirio de Nagasaki y del decomiso que se hizo de las mercancías del galeón español San Felipe que atracó en Japón, los españoles en Filipinas decidieron deportar a la mayoría de los japoneses que habitaban en Manila. En contraste, a partir de 1612, con el inicio de las promulgaciones anticristianas en Japón, esa comunidad nipona creció de manera considerable. Al parecer en un lapso de 10 años (1613-1623) aumentó a más del doble: en 1615 alcanzaban el número de 1,500, para 1623 eran ya tres mil (Borao, 2005: 13-17).

\section{Sobre cómo pudieron haber llegado los japoneses a Guadalajara}

Además de lo expuesto anteriormente, las relaciones del poder político en Japón sufrían varios reacomodos. Tenemos que tras la muerte de Hideyoshi en 1598, se formaron dos bandos que buscaban hacerse del poder central de Japón: los que respaldaban al heredero de Hideyoshi contra los que respaldaban a Tokugawa Ieyasu, quien era un señor feudal con mucha fuerza política, militar y económica. En el año de 1600 aconteció el combate definitivo entre ambas partes, conocido como la Batalla de Sekigahara, en la cual salieron triunfantes los seguidores de Tokugawa.

Quince años después, Ieyasu Tokugawa no sentía segura la permanencia de su linaje en el poder con la existencia del hijo de Hideyoshi, Toyotomi Hideyori, quien para ese año de 1615 contaba ya con 25 años de edad. Durante ese tiempo, éste se había resguardado en el castillo de Osaka, mismo que atacó Ieyasu Tokugawa para terminar definitivamente con ese linaje. Este episodio significó el último broche que aseguró la permanencia definitiva de los Tokugawa en el poder (por 250 años aproximadamente). Dos décadas más tarde Japón se cerraría al mundo exterior por más de dos siglos. 
Por esos años y bajo ese entorno inestable, sabemos que nacieron nuestros dos japoneses: Luis de Encío, probablemente alrededor de 1595 y Juan de Páez, en 1608. Con base en esta información, conjeturamos que Encío y Páez pudieron haber venido a la Nueva España en alguna de las siguientes travesías: el viaje de retorno desde Japón de Rodrigo de Vivero y Velasco en 1609; el viaje de retorno desde Japón de Sebastián Vizcaíno y que acompañó - de manera forzada - a la Misión Hasekura; el viaje de retorno desde Japón de fray Diego de Santa Catalina, y el viaje anual del Galeón de Manila a Acapulco. Veamos más de cerca esas cuatro posibilidades.

Rodrigo de Vivero y Velasco había sido gobernador interino de las Filipinas en 1608. En su viaje de retorno a la Nueva España en 1609, salió de Manila en tres galeones: el Santa Ana, el Santiago y el San Francisco; a los pocos días, las embarcaciones enfrentaron mal tiempo y el San Francisco, en el que viajaba Vivero, naufragó frente a las costas de Japón. Los pescadores de la aldea de Onjuku, en Chiba, rescataron a los náufragos. Rodrigo de Vivero aprovechó para presentarse como embajador del rey ante Ieyasu Tokugawa. Después de realizar gestiones diplomáticas, Vivero y Velasco salió del puerto de Uraga, en la bahía de Tokio, rumbo a la Nueva España en agosto de 1610 a bordo del San Buenaventura, embarcación construida a instancias del gobierno japonés. Varios autores concuerdan en afirmar que también iban a bordo veintitrés japoneses, al parecer comerciantes, que estuvieron bajo el mando de Tanaka Shôsuke (Mathes, 2006: 11; 1973: 96; Knauth, 1972: 198). El arribo a costas novohispanas se produjo a finales de octubre de ese mismo año, deteniéndose en Matanchén (en el actual estado de Nayarit), ${ }^{5}$ lugar desde donde Vivero envió una carta dirigida al rey de España en la que exponía los resultados de su embajada en Japón, incluyendo las ventajas de comerciar con ese país y la importancia del trabajo de los misioneros como avanzada de conquista.

Sebastián Vizcaíno por su parte fue designado por las autoridades novohispanas para realizar una nueva embajada diplomática en Japón, ello para dar seguimiento a las gestiones hechas por Vivero. Vizcaíno tenía asignado llevar de regreso a los veintitrés japoneses, ${ }^{6}$ presentar credenciales como em-

5. Sobre la llegada a Matanchén: era común que los galeones hicieran esta parada, por lo regular se hacía en el puerto de Navidad o en costas de Colima, de cualquier forma pudiéramos generalizar un rango geográfico entre las costas del actual Nayarit y Colima. El motivo de esta pausa rumbo a Acapulco era el despachar a un oficial de abordo con noticias y correspondencia para el virrey, y en algunos casos para el rey (Calderón, 1988: 574; Olveda, 1995: 70-72).

6. El cronista náhuatl, Chimalpahin, afirmó que sólo regresaron 17 (León Portilla, 1992: 145 y 146). 
bajador ante Hidetada (hijo y sucesor de Ieyasu) y ante Ieyasu, pagar cuatro mil pesos que se le habían prestado a Vivero para su regreso, solicitar permiso para sondear y demarcar las costas japonesas con el fin de actualizar las cartas geográficas que se tenían, y por último, buscar las míticas islas "Rica de Oro" y "Rica de Plata", las cuales se presumía estaban al este de Japón.

Vizcaíno y compañía salieron de Acapulco en marzo de 1611, arribando al puerto japonés de Uraga dos meses y medio después. A pocos días de su llegada, se entrevistó con las máximas autoridades japonesas. Para finales de octubre de ese mismo año inició las exploraciones de demarcación. Durante dicha labor aprovechó para detenerse a saludar a varios nobles de los lugares costeros por los que pasaba, destacando su visita a Date Masamune, daimyô de Sendai.

Este señor feudal era un personaje altamente influyente en la Corte de los Tokugawa, por tener lazos familiares con los hijos de Ieyasu. Date Masamune estaba muy interesado en que se instalaran misiones católicas en su territorio, quizá al igual que otros daimyô, con el fin de atraer a comerciantes europeos; entonces Date se entrevistó con fray Luis Sotelo, un franciscano que ya se encontraba en Japón y el cual se integró a la comitiva de Sebastián Vizcaíno.

Vizcaíno permanecería dos años más en Japón, durante los cuales atestiguó el incremento de la persecución cristiana. Su barco sufrió graves daños durante la búsqueda de las míticas islas de Oro y Plata. Así, en 1613 Vizcaíno tuvo que aceptar la oferta de Date Masamune para incorporarse a la embajada liderada por Hasekura Tsunenaga Rokuyemon, samurai al servicio de Date y que tenía como misión presentarse ante la corte española en Madrid y ante el Papa en Roma. Vizcaíno y sus hombres, fray Luis Sotelo, Hasekura y entre ciento cincuenta y ciento ochenta japoneses más, salieron rumbo a Acapulco a finales de octubre de 1613 en el San Juan Bautista, nombre que se le dio al barco de Date Masamune. Durante el viaje, Luis Sotelo con apoyo de los japoneses, tomó el mando del barco y confinó a Vizcaíno a su camarote en calidad de simple pasajero. Tres meses después de haber zarpado, tocaron tierra novohispana en las costas de Colima, y pocos días más tarde, arribaron al puerto de Acapulco (finales de enero de 1614). Vizcaíno llegó en un estado de salud precario.

Hasekura y Sotelo se dirigieron a la ciudad de México con 80 japoneses aproximadamente, y el resto permanecería en Acapulco esperando el regreso de Hasekura. Los nipones estuvieron varios meses en la capital novohispana, lugar donde todos fueron bautizados, con excepción de Hasekura, que 
fue bautizado en Madrid. Hasekura partió de la ciudad de México con un grupo reducido de japoneses: unos 30; a los demás se les ordenó regresar a Acapulco. Hasekura salió de Veracruz rumbo a España en junio de 1614. En Europa, después de pasar por Sevilla, llegó a Madrid. En noviembre de 1615 lo recibió el papa Paulo V y retornó a la Nueva España en 1617. Ya en la Nueva España, tras recorrer todo el camino de regreso hasta Acapulco, Hasekura se encontró con que muchos - si no es que la mayoría- de los japoneses ya se habían regresado a Asia, otros ya tenían esposa e hijos ahí en el puerto, otros más se internaron en la Nueva España en busca de una nueva vida (quizá por ser conversos y por estar enterados de la difícil situación del cristianismo en Japón. El galeón de Manila, aparte de traer mercancías, traía noticias de aquellas tierras). Sumado a lo anterior, hay que decir que una decena de japoneses aproximadamente se quedaron en España (Valencia Japón). En abril de 1618, Hasekura y unos cuantos japoneses salieron rumbo a Manila. En aquella ciudad tuvieron que esperar hasta 1620 para regresar a Japón debido a la férrea persecución anticristiana. Desde luego que Hasekura tuvo que abjurar de la fe cristiana para poder ingresar a Japón de nuevo.

En cuanto a la embajada de fray Diego de Santa Catalina, ésta fue enviada por el rey español y el Consejo de Indias para responder a una misiva que Ieyasu Tokugawa había enviado al rey con Alonso Muñoz, quien viajó en 1610 con Vivero en su retorno a la Nueva España. En esa carta Ieyasu solicitaba el envío de mineros expertos a Japón y el acceso a la navegación transpacífica, dominada por los españoles. Diego de Santa Catalina salió de Acapulco en 1615 y se encontró con un Japón convulso después de las batallas de Osaka. Por otra parte, Diego de Santa Calina, que llevaba la mala noticia de la negativa del rey de conceder a los japoneses el acceso a la ruta transpacífica, además de que su embajada estaba compuesta por franciscanos religiosos, no fue bien recibido en Japón y fue enviado de regreso a la Nueva España custodiado por japoneses. Estos últimos aprovecharon el viaje para cargar la embarcación de mercancías para comerciar en Acapulco y en la ciudad de México.

Fray Diego de Santa Catalina tenía en sí órdenes de no traer en el viaje de regreso a más comerciantes japoneses, lo cual le fue imposible evitar. En dicho regreso, el San Juan Bautista, para rematar, se vio envuelto por calamidades naturales. Por fin lograron hacer una parada intermedia en costas de Colima a finales de febrero de 1617; Diego de Santa Catalina envió desde ahí una carta informando lo sucedido en la misión; dicha carta pasó primero por la Real Audiencia de Guadalajara, para luego llegar al Marqués de Guadalcázar (virrey 
de la Nueva España), quien finalmente remitió información de lo sucedido al rey de España. Sin duda, ése era el fin de las relaciones entre ambas partes, que quedarían a la espera de coincidir en mejores tiempos.

Finalmente, la otra posibilidad que pudieron haber tenido los japoneses para embarcarse a la Nueva España, fue la brindaba por la Nao de China. Si consideramos que en Manila, Filipinas, existía una colonia numerosa de japoneses, es probable que algunos de ellos hayan viajado en el Galeón de Manila a la Nueva España y que ya no hicieran el viaje de regreso. Recordemos que los galeones que iban de Manila a Acapulco y viceversa, hacían un viaje por año. También pudiéramos tener en cuenta que antes de que el Galeón llegara a Acapulco, hacía una parada en las costas que abarcan los actuales estados de Nayarit, Jalisco y Colima, lo cual nos parece importante señalar por la cercanía a Guadalajara. Más aún, entre 1612 y 1623, una gran cantidad de japoneses cristianos huyeron de su país, y muchos de ellos fueron a dar a Manila. Para añadir más información a este argumento bien vale aquí citar a José Eugenio Borao, quien muestra datos duros del número de barcos que hicieron el viaje de Japón a Manila, todos ellos cargados de japoneses (en su mayoría cristianos huyendo de la persecución anticristiana): tenemos entonces que en 1615 fueron cinco barcos, para 1617 lo hizo uno, en 1618 tres más, y en 1619 nuevamente uno (Borao, 2005: 16). Se refiere obviamente a barcos con licencia oficial, o sea que no se están contando aquí los que salieron sin permiso del gobierno japonés.

Si lo anterior aplicara en el caso de nuestros japoneses, quiere decir que de Japón viajaron primero a Manila, y que una vez ahí, se embarcaron en la Nao de China con rumbo a la Nueva España, llegando específicamente a la Nueva Galicia en una posible parada intermedia en costas del actual estado de Nayarit.

\section{Luis de Encío}

Llegamos entonces a la historia específica de uno de los japoneses que llegaron a Guadalajara dentro del marco histórico antes descrito. Nos referimos a Luis de Encío. Por los documentos consultados sabemos con certeza que Luis de Encío comenzó a radicar en Guadalajara al menos desde el año 1634. Sabemos también que Encío se casó con una indígena de nombre Catalina de Silva y que su única hija, Margarita, contrajo matrimonio con Juan de Páez, 
probablemente en 1636 . Ahora bien, ¿cuándo llegó Encío a estas tierras? Hasta ahora no lo sabemos con certeza, pero Calvo y algunos registros consultados dan algunas pistas que nos permiten suponer que Encío estuvo al menos desde 1620 en el pueblo de Ahuacatlán, cercano a Bahía de Banderas (conocida en aquella época como Bahía de Tintoque).

$Y$ viene una nueva pregunta: ¿cómo se conocieron Luis de Encío y Juan de Páez? En una primera impresión pudiéramos pensar que llegaron juntos, pero tenemos datos que los separan: al parecer Juan de Páez, desde que llegó a la Nueva España, habitó en Guadalajara, ${ }^{7}$ mientras que Luis de Encío, según parece, tardó más de 10 años en avecindarse en esta ciudad, lugar donde es probable que se hayan conocido.

Creemos que Luis de Encío, trabajando ya como comerciante viajero, en alguna de sus estadías temporales en Guadalajara, cercanas a los prime-

Creemos que Luis de Encío, trabajando ya como comerciante viajero, en alguna de sus estadías temporales en Guadalajara, cercanas a los primeros años de la década de 1630, quizá fue que conoció a Juan de Páez, quien suponemos era entonces un joven de poco más de 20 años de edad; probablemente la afinidad racial —refiriéndonos a rasgos físicos comunesdebió ser factor para que se conocieran, pero más que eso, el enterarse de que ambos eran oriundos del lejano Japón ros años de la década de 1630, quizá fue que conoció a Juan de Páez, quien suponemos era entonces un joven de poco más de 20 años de edad; ${ }^{8}$ probablemente la afinidad racial —refiriéndonos a rasgos físicos comunes-debió ser factor para que se conocieran, pero más que eso, el enterarse de que ambos eran oriundos del lejano Japón.

Luis de Encío, según supone Thomas Calvo, empezó su carrera comercial en estas tierras como buhonero (vendedor ambulante), actividad que lo debió

\footnotetext{
7. ARAG; ramo civil, caja 2, exp. 18 (C-12-18); "Autos en razón de lo que la ciudad pretende cerca de que aya Alhondiga [...]"; fojas 14v.-15f.

8. Ídem.
} 
haber traído a Guadalajara tras hacerse de contactos que lo capitalizaron para emprender una nueva etapa en su vida en la Nueva Galicia. Fue en 1634 cuando Encío firmó un contrato como socio del mercader novohispano Francisco de Reinoso, comprometiéndose a atender una tienda en Guadalajara, hecho que pudo haber determinado que Encío radicara de manera permanente en esta ciudad.

\section{Luis de Encío en la sociedad tapatía del siglo XVII}

En una primera impresión, al oír sobre este tema, se pudiera pensar en lo extraño que pudo haber sido encontrarse con un japonés en la Guadalajara del siglo XVII, pero la realidad era otra: en Guadalajara ver a una persona con rasgos raciales característicos del Este asiático fue algo común. Por ejemplo, en los registros sacramentales del siglo XVII del Sagrario Metropolitano de Guadalajara hemos encontrado a más de 20 personas con esta descripción racial.

Además, como bien dice Thomas Calvo, "esta sociedad pionera no fue xenófoba" (Calvo, 1992: 161), y más que nada, se reconocía, como hasta la fecha se hace, el éxito profesional sin importar la procedencia de las personas, siempre y cuando éstas mostraran verdaderas actitudes de adaptación. Luis de Encío debió haber tenido varias dificultades al respecto, empezando por el idioma - y más tarde con la escritura - la comida, la forma de vida en general. Calculamos que para 1620, año en que se piensa que llegó al pueblo de Ahuacatlán, él debió tener 25 años de edad, y que incluso, según señala Hayashiya, pudo haber sido un samurai en Japón. No obstante, se esforzó por encajar plenamente en esta sociedad, en la cual llegó a tener sus momentos protagónicos, como cuando se hizo del monopolio de la venta de vinos de coco y mezcal en 1643 (Calvo, 1992: 284 y 285), o cuando fue proveedor de algunos gustos comestibles que el presidente de la Real Audiencia compraba para su esposa (Calvo, 1992: 424).

Cierto es que su ascenso económico tampoco fue el suficiente como para hacer que la gente olvidara su origen; incluso uno de los registros documentales que hemos consultado nos hace pensar que en la vida diaria era llamado o conocido como "Luis, el chino". ${ }^{9}$ Aunque éste pudo haber sido un alias cotidiano, no dudamos que en algún momento el término "chino" se

9. AhAG; sección: Gobierno, serie: Parroquias, Catedral: caja 1 [s. n. exp.] (1640); “Cuentas que da el Sr. Racionero Don Andrés por la fábrica como tesorero [...]"; foja $9 f$. 
haya utilizado en su persona de manera despectiva, y esto tiene que ver con el hecho de que durante varias décadas la Nao de Manila traía consigo esclavos filipinos, llamados comúnmente "chinos"; y lo despectivo del término no tiene que ver tanto en sí con aspectos raciales, sino económicos. En el caso de Encío, como en otros tantos donde tiene que ver el origen étnico, quizá posibles dejos de envidia eran los que podían llevar a utilizar la descripción racial de manera despectiva.

Fue en la década de 1640 cuando la curva económica de Encío alcanzó su nivel más alto (para después irse en picada), siendo ya un señor cuarentón, mejor adaptado, sabiendo incluso firmar en español. A mediados de la década de 1630 había llegado a Guadalajara como socio menor de una tienda y cuya aportación era sólo atenderla (Calvo, 1992: 381), y poco más de 10 años después las cosas cambiaron: ahora era él quien aportaba el capital para poner una tienda. ${ }^{10}$ Tal punto pico de la curva económica de Encío coincide con el punto pico de apadrinamientos de "hijos de la Iglesia" (niños huérfanos o abandonados) que hizo junto con su esposa Catalina, que según nuestros registros suman la cantidad de nueve, de los cuales muy probablemente se hicieron cargo de su crianza, y bien sabemos que para sustentar a esa cantidad de niños había que tener cierta liquidez económica.

Es importante que en este texto demos el dato de la ubicación de la tienda y casa de Luis de Encío, la cual rentaba a la Iglesia. Tal propiedad se ubicaba en las inmediaciones de la Plaza Mayor (actual Plaza de Armas), específicamente, según nuestras fuentes, creemos que se trata de la esquina de las calles actualmente llamadas Pedro Moreno y Avenida 16 de Septiembre, en la acera de enfrente de la Plaza de Armas. Luis de Encío comenzó a alquilar ese predio desde $1640^{11}$ y por lo menos mantuvo ahí su negocio y vivienda hasta 1655. Pagaba una renta anual de 84 pesos y formaba parte de un grupo de 23 arrendatarios a quienes el clero tapatío rentaba alguna propiedad. ${ }^{12}$

En 1647, Encío firmó con el también mercader, Francisco de Castilla, una sociedad para poner una tienda de "mercaderías y menudencias comestibles". La tienda era en sí la misma que ya tenía Luis de Encío; al parecer se trató de un resurtido con una inversión por parte del japonés de 1,340 pesos, más 203

10. AipJ; Notarios: Diego Pérez de Rivera, Libro 3ro. (1646-1647); ff. 149v.-151f.

11. AHAG; op. cit; fojas 1f., 3v.-4f.

12. AHAG; sección: Gobierno, serie: Parroquias, Catedral: caja 1 [s. n. exp.] (1644); "Cuentas de la fabrica desta iglesia que dio el Br. d. Pedro de Useta Bracamonte"; 9 fojas. 
pesos que puso Castilla; este último tendría que atenderla, llevando Encío el mando de dicha asociación, aunque al final las ganancias se repartirían por partes iguales. Vale la pena aquí abundar sobre Francisco de Castilla. Existe un registro de entierro (en el Archivo del Sagrario Metropolitano de Guadalajara) del año 1661, de un Francisco de Castilla "chino", ¿se tratará del socio de Encío? De ser así, podemos decir que aquél experimentó un ascenso económico parecido al de Encío, es decir, bajo la misma fórmula. Esto lo decimos porque en ese mismo registro de entierro quedó asentado que Castilla dejó una capellanía por 2,000 pesos impuestos sobre sus propiedades. También llama nuestra atención al respecto un registro de entierro de 1658, de María de Silva "china casada con Francisco del Castillo"; viene de nuevo la misma pregunta: ¿se tratará del mismo personaje o será sólo una coincidencia de un casi homónimo?

Pero en sí, de lo anterior lo más importante para nuestro estudio es lo que afirma Thomas Calvo en cuanto a señalar a Luis de Encío como "el centro de todo el núcleo asiático neogallego" (Calvo, 1989: 162); pensando pues en el aparente origen asiático del socio de Encío, además de su relación comercial con Francisco de Castilla "chino", y con su yerno japonés Juan de Páez, se conocen al menos dos casos más de asiáticos relacionados con Encío: el primero de ellos es el que nos revela el registro de entierro de Agustín López de la Cruz (1642), donde se afirma que era de "nación Japón", y dejó como su albacea a "Luis de Encío Japón". El otro caso sería el que cita Calvo, de un tal Juan de la Cruz, "de nación chino" del pueblo de Sayula, que en 1643 otorgó una carta poder a Encío. ${ }^{13} \mathrm{Si}$ sumamos entonces el caso de Francisco de Castilla, el argumento de Calvo quedaría aún más afianzado.

Para cerrar aquí este caso del japonés Luis de Encío, nos gustaría hacer un ejercicio imaginativo en el que vemos a este hombre en el momento que recién llegó a la Nueva España, siendo alguien decidido, con carácter fuerte, con su probable pasado samurai, ubicado de pronto en un lugar enteramente desconocido para él en todos aspectos, luchando por adaptarse y encajar; después buscó sustento como comerciante, su empuje lo hizo dar un primer ascenso económico ubicándolo en la ciudad con mayor dinamismo comercial

13. Sobre el registro de Agustín López de la Cruz: AHAG; Microfilmes: Libros de registros sacramentales del ASmg [Rollo: 1511], Libro 3ro. Mixto (Entierros: 1641-1647); folio 2f. Sobre Juan de la Cruz "de nación chino": Thomas Calvo (1989: 162). 
de la región: Guadalajara. De ahí el ascenso no se detuvo, hasta que la edad misma lo hizo venir a menos.

Luis de Encío murió en 1666, ya viudo y de unos 71 años aproximadamente; en su testamento se queja amargamente de estar en la ruina, producto de malos negocios y del mal manejo del dinero; señala que en sus últimos días sobrevive gracias a la asistencia de su yerno Juan de Páez, a quien llama de manera afectuosa "hijo". Es inevitable imaginar a un Luis de Encío en su lecho de muerte acompañado por su hija, por su yerno Juan de Páez y por los hijos de éstos, o sea por sus nietos. No encontramos su registro de entierro, pero con base en su testamento, creemos que murió entre los últimos días de septiembre y los primeros de octubre de 1666. Como era común en esa época, fue sepultado en la Catedral.

\section{Juan de Páez. El círculo familiar}

Ahora pasemos al caso de Juan de Páez. Las fuentes consultadas comienzan a arrojarnos múltiples registros relacionados con Juan de Páez a partir del año 1637. En ese año el japonés tendría unos 29 años de edad, y fue cuando nació su primer hijo, a quien bautizaron él y su esposa Margarita con el nombre de Luis: igual que el de su abuelo Luis de Encío. Suponemos que Margarita de Encío y Juan de Páez quizá se casaron entre 1635 y 1636. Margarita - especulamos - tendría al menos 15 años de edad. Valdría imaginar que probablemente Luis de Encío se sentía complacido de entregar a su única hija a un hombre de su mismo lugar de origen, que además tenía una sólida formación, lo cual podía ser garantía de la seguridad y felicidad futura de su amada hija. Al menos en lo que a prosperidad económica se refiere, Luis de Encío no se equivocó.

Juan de Páez y su esposa Margarita fundaron una amplia familia sobre la base de una sólida unión matrimonial que sólo se logró romper con la muerte del primero (en 1675). En cuatro décadas de matrimonio, Margarita y Juan procrearon nueve hijos. La mayoría fueron mujeres, seis en total: María fue la tercera de la prole y la primera hija mujer; sus hermanas menores fueron Josepha, Juana, Petrona, Francisca y Margarita (todas procrearían en su momento a los nietos de Juan y Margarita, que en total fueron 13; algunos de ellos nacidos después de la muerte de su abuelo Juan). Los hijos varones fueron Luis, Andrés y Juan. De estos tres, sólo Andrés llegó a edad adulta. 
Luis y Juan probablemente tuvieron una muerte temprana pues no son mencionados por sus padres en sus testamentos.

La familia Páez-Encío formó parte del núcleo privilegiado de la sociedad tapatía de la época. La obtención de la mayordomía de la Catedral por parte de Juan de Páez, quizá fue el medio eficaz — junto con los albaceazgos- que encontró para codearse con la alcurnia de la sociedad, el clero y las autoridades coloniales de la Nueva Galicia. Son muchas las ocasiones en que los miembros de la familia Páez-Encío aparecen en registros de bautismos como padrinos de hijos - legítimos - de familias tapatías, y también son muchas las ocasiones en que encontramos a Juan de Páez como albacea de los bienes de hombres prominentes. La sagacidad de Páez en los negocios, a la par que hacía prosperar los de la Iglesia con el astuto manejo de los diezmos, le proporcionó los contactos y los medios para amasar una fortuna considerable.

¿Cómo encajan los Páez en la sociedad tapatía? Como ya hemos señalado, las actividades de Páez lo convierten en uno de los comerciantes más ricos de la ciudad. La información disponible indica que la casa de los Páez se encontraba en el primer cuadro de la ciudad sobre la calle de San Agustín, probablemente ocupando un cuarto de manzana, que años más tarde se subdividió a la usanza de los tiempos. Por los registros y planos consultados sabemos que la finca de los Páez se ubicaba, partiendo del convento de San Agustín hacia el poniente, en la siguiente manzana; es decir, actualmente estaría sobre la calle Morelos entre el templo de San Agustín y el Palacio de Gobierno. No sabemos cuándo adquirió Páez ese solar, pero probablemente ello coincidió con el periodo de mayor auge económico del japonés.

\section{Los albaceazgos de Juan de Páez}

Aunque Juan de Páez aparece siempre en los documentos con la denominación "mercader", en realidad su desenvolvimiento profesional figura específicamente en la proveeduría de servicios de administración de bienes, préstamos de dinero, especulación en compra-venta de plata, ejecución de compras, ventas y arrendamientos de bienes de terceras personas (ganado, tierras, inmuebles, esclavos, etcétera), cobros, así como representación legal de sus clientes, sobre todo en lo que a gestión de trámites burocráticos se refiere.

El desenvolvimiento y dominio de Páez en la ejecución de estos servicios pueden describirse como sobresalientes. El conocimiento técnico que poseía como hombre de negocios es algo innegable, y como una prueba fundamen- 
tal de ello fue la notable cantidad de personas que lo nombraron albacea en sus respectivos testamentos, siendo el albaceazgo una parte clave para la transmisión de bienes patrimoniales, requiriendo de dotes técnicas para la ejecución de dicha tarea.

Básicamente un albacea administraba los bienes del difunto durante el tiempo en que se procedía a la repartición legal de éstos; al repartirse, tenía que dar cuenta de la administración que había hecho de esos bienes. También le correspondía hacer el pago y el cobro de deudas heredadas por el difunto. En los días inmediatos al fallecimiento, se tenía que encargar de las disposiciones funerarias, de las cuales emanaban gastos tales como la misa de cuerpo presente, el entierro, el pago de las misas póstumas, pago de mandas dejadas testamentariamente y otros; para cubrir esos gastos se tomaba $20 \%$ (un quinto) de los bienes dejados. Podemos ir vislumbrando entonces que se tenía que dejar como albacea o albaceas, a personas de entera confianza, decisión que en buena medida debía basarse en que la persona o personas elegidas tuvieran la capacidad técnica para ejercer esa disposición.

Ahora bien, ¿cuál era la conveniencia de ser albacea testamentario? El albaceazgo muchas veces era para el albacea parte de una estrategia de ascenso social y patrimonial. Ya lo explica Thomas Calvo en el caso de la Guadalajara del siglo XVII, en cuanto que el albaceazgo fue "uno de los recursos más eficaces" utilizados por varios hombres de negocios "para extender su poder sobre capas importantes de la sociedad", ya que estamos hablando del acceso a "la gestión de fortunas, a veces considerables, en provecho de herederos, pero también del albacea, cuyo peso moral y económico se reforzaba" (Calvo, 1992: 387).

Precisamente lo anterior es notorio en el caso de Juan de Páez, en quien podemos apreciar cómo en la década de 1640 hizo un trabajo importante de relaciones públicas que en un futuro lo catapultarían a lo más alto de la sociedad tapatía. Vemos entonces que en 1643 aparece como albacea por primera vez, por disposición testamentaria de Juan Jiménez, ${ }^{14}$ probable comerciante de la ciudad. En esa misma década Páez recibiría ese mismo encargo en otros tres casos, dos de ellos de vecinos naturales de España: el mercader Juan de Arce, y don Julián de Cárdenas y Monreal; el otro fue el de don Mateo Ramírez de Alarcón, deán del Cabildo Eclesiástico; este último pudiera sobresalir de

14. AHAG; Microfilmes: Libros de registros sacramentales del ASMG [rollo: 1511] Libro 3ro. Mixto (Entierros: 1641-1657); f. 4v. 
los demás hasta ahora nombrados, por tratarse del primer clérigo en dejar como su albacea a Juan de Páez.

La década de 1650 fue para el japonés-tapatío la época en que comenzó a recoger las grandes cosechas de lo que sembró en la década anterior, y para prueba de ello está precisamente el aumento de las designaciones que recibió como albacea en esos años: entre 1650 y 1658 fue nueve veces nombrado como albacea testamentario; siete de ellas por miembros del clero de Guadalajara. Las otras dos se trataron de Catalina Bravo (viuda), y Alonso Núñez, ${ }^{15}$ quien fue por muchos años boticario y enfermero del Hospital de San Miguel, y en cuya administración desempeñaba un rol protagónico.

A los casos anteriores se sumarían en los años siguientes y hasta 1674 (un año antes de la muerte de Páez), 15 designaciones más, entre los cuales siguen apareciendo clérigos, aunque el caso que más destaca podría ser el de una autoridad civil: don Jerónimo de Aldas y Hernández, oidor de la Real Audiencia de Guadalajara, quien falleció en julio de 1663. ${ }^{16}$

Retomando el asunto de los clérigos, es de llamar la atención que casi 50\% de los albaceazgos de Juan de Páez provengan precisamente de miembros del clero tapatío. Al respecto, Thomas Calvo nos da una clara explicación:

[La posibilidad del albaceazgo] es frecuente, en un siglo y en una sociedad donde muchas de las fortunas son eclesiásticas, es decir, sin herederos directos que acaparen inmediatamente la sucesión [...] Los comerciantes eran los más indicados para asumir el papel de albaceas, siendo hombres de negocios, inteligentes, a veces hombres de confianza de los dueños de grandes fortunas o de las instituciones (Calvo, 1992: 387).

No nos queda duda de que Juan de Páez fue el hombre que más confianzas se ganó entre los clérigos radicados en Guadalajara durante el tiempo que aquél estuvo activo como hombre de negocios. En sí, en general su nombre como albacea es el más recurrente en los registros de entierro del Sagrario

15. La fortuna del boticario Alonso Núñez no debió haber sido cosa menor, pues simplemente en un registro notarial de 1647, encontramos que éste le presta a Juan de Páez la cantidad de 2,200 pesos con un plazo de pago de un año. Al interpretar este registro, vemos también la confianza existente por parte de Núñez hacia el japonés, al prestarle esta cantidad sin necesidad de aval o fiador. Véase: AIPJ; Notarios: Diego Pérez de Rivera; Libro 3ro; ff. 153v.-154f.

16. AHAG; Microfilmes: Libros de registros sacramentales del ASMG [rollo: 1512] Libro 5to. Mixto (Entierros: 1657-1667); folio 127f. 
Metropolitano de Guadalajara de los años 1634 a 1674. Según los registros consultados, en total 28 personas nombraron a Páez como su albacea.

Juan de Páez: mayordomo de la Catedral de Guadalajara

Una de las facetas más destacables de la vida profesional de Juan de Páez, fue ser mayordomo de la "rentas decimales" de la Catedral de Guadalajara, ello durante poco más de 20 años. Esta ocupación lo catapultó, sin duda, económicamente aún más y lo posicionó, a él y a su familia, de manera indiscutida, dentro de la élite tapatía del siglo XVII.

\section{El diezmo}

Antes de proceder a examinar el papel que Juan de Páez desempeñó como mayordomo de la Catedral, nos es necesario presentar un breve esbozo de cómo estaba constituida la administración del diezmo.

Desde la Edad Media, el cobro del diezmo por parte de la Iglesia católica se volvió regla fiscal en todos aquellos territorios donde imperaba el credo cristiano. Como la propia palabra lo indica, el diezmo consistía en la entrega de $10 \%$ de los frutos o ganancias percibidas lícitamente por los feligreses; esa carga fiscal servía para sustentar a la "maquinaria" proveedora del culto cristiano (Iranzo, 1991).

A finales de 1501 el papa Alejandro VI concedió todos los diezmos americanos a la Corona española, con la condición de que ésta asegurara los ingresos necesarios para el funcionamiento de la Iglesia en el "Nuevo Mundo" (Borah, 1986: 62 y 63). De esta manera, el Estado español estableció reglas claras para la repartición de dicha recolección (ejecutada y administrada por los mismos ministros de la Iglesia, pero con el debido seguimiento de las autoridades reales).

De acuerdo con tales reglas, lo recaudado en cada obispado se dividía en dos partes iguales. Una de esas mitades se partía a su vez en otras dos partes: una era para el obispo y la otra para el Cabildo Eclesiástico. El otro 50\% se dividía en nueve partes (novenos): dos novenos pertenecían a la Corona, uno y medio a la construcción y reparación de las catedrales y templos parroquiales, otro noveno y medio al establecimiento y mantenimiento de hospitales, y los cuatro novenos restantes eran para el pago de salarios de los demás sacerdotes (Borah, 1986: 65; Calvo, 1992: 244 y 262). 
Según el historiador Woodrow Borah, este impuesto era uno de los más importantes cobrados en la Nueva España, siendo "fuente primordial de ingresos para la Iglesia" (Borah, 1986: 61). Los bienes y productos con tasación diezmal eran particularmente los agrícolas, incluyendo desde luego al ganado, que en el caso de la Nueva Galicia era económicamente importante.

\section{La mayordomía de Catedral}

De acuerdo con la historiadora Leticia Pérez Puente, el mayordomo tenía la obligación de diligenciar las deudas que se le debieran a la Catedral por concepto de diezmos y rentas; de igual forma, le correspondía llevar a los deudores ante la justicia eclesiástica. Su designación o renovación se hacía cada tres años. Era en sí, un brazo ejecutor dentro de los procedimientos administrativos de la recaudación de la rentas decimales de la Iglesia. Había dos componentes más para llevar a cabo estas funciones, y con los cuales se tenía que coordinar el mayordomo: los jueces hacedores y el contador (Pérez Puente, 2001: 22).

Los jueces hacedores conformaban el tribunal de rentas decimales o "la haceduría"; se trataba de dos clérigos nombrados por el Cabildo Eclesiástico. Su función principal era la supervisión de "la recaudación y distribución del diezmo, para lo cual elaboraban los contratos con los arrendatarios, revisaban las cuentas generales [así como] las de los administradores y arrendatarios" (Pérez Puente, 2001: 22). Por su parte, el contador ajustaba las cuentas de lo procedente del diezmo y demás rentas de la Iglesia, presentando ante el Cabildo informes anuales de estas mismas, y en tales informes se incluían también los gastos ejercidos.

Lo anterior aplicaba principalmente en la Catedral Metropolitana de la ciudad de México, sede del Arzobispado de México, así como en casi todas las diócesis pertenecientes a ese Arzobispado. No obstante, para el caso de Guadalajara (sede del obispado de Guadalajara, cuya territorialidad era el reino de la Nueva Galicia), suponemos que al menos en intención, se trató de adecuar ese mismo orden administrativo para el cobro y manejo de los diezmos y demás rentas, según constan algunos registros del Cabildo Eclesiástico de esta ciudad. 
Sobre la elección de Juan de Páez como mayordomo

La designación de Juan de Páez como mayordomo fue consecuencia de un pleito entre el Cabildo Eclesiástico y el obispo, que entonces era Juan Ruiz Colmenero. El problema se originó por la posesión del obispo en turno de la llamada "caja de tres llaves", que era donde se guardaba el dinero recolectado del cobro del diezmo y demás rentas. De acuerdo con la información documental consultada, desde 1622 el obispo en turno había sido el único encargado del manejo del dinero de los diezmos, ya que no se había nombrado mayordomo. Así, el Cabildo se quejaba de que al no haber un encargado permanente de llevar las cuentas, había poca claridad acerca de los ingresos y egresos. Ante tal situación, el Cabildo decidió en junio de 1648 que se nombrara un mayordomo. Fue entonces que Juan Ruiz Colmenero, obispo, se opuso a tal resolución.

Así las cosas, el caso fue llevado hasta la Real Audiencia de Guadalajara y al Consejo de Indias. Los años de 1651 y 1652 fueron de estira y afloja. Al final, apoyados por la cédula real de 1653, la razón fue dada al Cabildo, permitiéndoles nombrar a un mayordomo. Así, el 24 de octubre de 1653, reunidos el obispo Juan Ruiz Colmenero y los miembros del Cabildo, se mandaron emitir los edictos para elegir a un mayordomo entre quien se postulase para dicho cargo. Ocho meses después lo designaron por fin: el 23 de junio de 1654, Juan de Páez era nombrado mayordomo de "todas las rentas decimales" de la Catedral de Guadalajara.

Según se asienta en el Acta de Cabildo, Juan de Páez se haría "cargo de todo el dinero que está en la caja de tres llaves, y de todos los papeles de entradas y salidas desde que el dicho Señor Obispo [Juan Ruiz Colmenero] se hizo cargo de dicha caja". ${ }^{17}$ Como vemos, ejercería responsabilidades más amplias de lo que indica la descripción que hicimos anteriormente. Pero no imaginemos una designación romántica de Juan de Páez por parte de la Iglesia; el nombramiento de Páez se debió a que fue el mejor postor. Efectivamente, Páez ofreció dar 10,000 pesos de fianza para obtener el cargo. ${ }^{18}$ Aunque habrá que sumar también la buena relación que guardaba con varios clérigos de Guadalajara, algunos de los cuales ya lo habían nombrado como su albacea. ${ }^{19}$ Por

17. ACEG; Libro VII de Actas Capitulares del Cabildo Eclesiástico de Guadalajara (1651-1707); f. 41f.

18. ACEG; ibídem; ff. 84f.-84v.

19. AHAG; Microfilmes: Libros de registros sacramentales del ASMG [rollo: 1511] Libro 3ro. Mixto (Entierros: 1641-1657); ff. 9f., 16v., 19f. y $23 f$. 
otro lado, el asunto de las rentas decimales no le era para nada ajeno: ya en los años de 1651 y 1652 Páez había obtenido el arrendamiento de los diezmos de Compostela. ${ }^{20}$ La Iglesia se valía de dos maneras para cobrar los diezmos: una era la recaudación directa y la otra el arrendamiento; esta segunda opción permitía a particulares cobrar tales rentas, pagando un estimado de dinero por adelantado a la Iglesia.

\section{Arrendatario de diezmos}

No sabemos hasta qué punto Juan de Páez sacó provecho como mayordomo en lo que al arrendamiento de diezmos se refiere, pues ya desde antes de ocupar este cargo él accedía a este tipo de negocio. Sin embargo, una vez hecho de la mayordomía, podía contar con información privilegiada, lo cual le pudo significar una mejor toma de decisiones a la hora de invertir lo del cobro de diezmos.

Tenemos así que sólo un año después de su designación como mayordomo, accedió al cobro de los diezmos de los partidos del Valle de Tlaltenango y de la Villa de Jerez (ubicados en el actual estado de Zacatecas). Según parece, el arriendo de estos "desmatorios" era muy competido, ya que en 1656, aún teniendo Juan de Páez derecho sobre ellos, el Cabildo le informó que había una oferta - seguramente mayor a lo ofrecido por Páez - para acceder a ellos. La cantidad ofrecida era de 1,400 pesos, a lo que el mayordomo respondió ofreciendo 1,405 pesos, una diferencia exageradamente corta, pero suficiente para que los clérigos rechazaran el otro ofrecimiento. Vemos cómo incluso hasta en sus últimos años de vida siguió accediendo a este tipo de inversión, administrando el cobro de los diezmos de las haciendas de Jocotepec y de Cuisillos correspondientes a los años 1674 y 1675.

\section{Entre altibajos y mutua complicidad}

Sería ilusorio pensar que tratándose de manejo de dinero, todo fuera miel sobre hojuelas para Juan de Páez como mayordomo de Catedral. Al poco tiempo de ser nombrado como tal, don Juan Serrato y Cañas se incorporó como miembro del Cabildo Eclesiástico y como juez hacedor de las rentas decimales.

20. ACEG; op. cit; f. 10v. 
Suponemos que la relación entre mayordomo y juez hacedor no marchó del todo bien, quizá habiendo desacuerdos en los asuntos de la administración de los diezmos. Lo anterior lo interpretamos por la protesta que hizo el canónigo Serrato ante los demás miembros del Cabildo: el 18 de septiembre de 1657 se quejó de que Juan de Páez no había dado los 10,000 pesos de fianzas que debía pagar por ocupar la mayordomía.

Lo curioso es que después de dicha protesta no se trató más el asunto, o al menos no se asentó más en las actas del Cabildo Eclesiástico; ni siquiera Juan Serrato reiteró dicha protesta. Tal silencio pudo obedecer a un posible arreglo fuera del Cabildo. De lo que hay más certeza es de que más allá de los 10,000 pesos, al ser nombrado Páez como mayordomo, éste se comprometió a pagar puntualmente los salarios de los prebendados, hubiera o no dinero en la caja para ello.

Es de pensar que el nuevo mayordomo fue cumpliendo puntualmente con esos pagos, desentendiéndose entonces los señores capitulares de exigirle a Páez el pago de los 10,000 pesos, e incluso actuando en complicidad con él ante la protesta del padre Serrato. Algo tendría que ver también que Páez disimulaba los atrasos de los pagos de deuda que tenían los miembros capitulares con la caja de tres llaves. ${ }^{21}$

No obstante dicha complicidad, en 1662 Páez fue llamado a rendir cuentas del dinero perteneciente a la fábrica de Catedral (entradas y salidas para la construcción y ornamentación de la Catedral), las cuales presentó haciendo informe de lo ejercido desde junio de 1654 hasta agosto de 1662, obteniendo el visto bueno del Cabildo. Tal parece que a partir de ahí la confianza capitular aumentaría aún más hacia su mayordomo.

En cuanto a los 10,000 pesos, es casi seguro que nunca los haya entregado, aunque 20 años después de fungir como mayordomo, el Cabildo declaraba que en lo referente a la fábrica de Catedral se encontraba en deuda con el mayordomo, porque éste la había mantenido al día. ${ }^{22} \mathrm{Y}$ es que, a final de cuentas, a lo largo del tiempo que estuvo Páez en ese cargo el Cabildo lo obligaba a reparar fincas propiedad de la Iglesia por cuenta propia, y en teoría, una vez terminadas las reparaciones el Cabildo autorizaría el pago de lo desembolsado por Páez, pero es probable que no siempre sucediera así.

21. Ibídem; [sobre la protesta de Juan Serrato y Cañas:] f. 84f.-84v; [sobre el pago de salarios:] f. 41f; [sobre deudas de los señores capitulares:] ff. 49v.-50f.

22. Ibídem; f. 178f.-178v. 
Es un hecho que la mancuerna Páez-Iglesia iba una a una, manteniéndose en equilibrio: después de haber librado las protestas de Juan Serrato y el llamado a cuentas de 1662, Páez solicitó en 1667 que se le pagara salario por sus servicios como mayordomo de los casi 13 años que llevaba como tal (sabedor de que el estado de las finanzas eclesiásticas lo permitía). Estamos hablando de 300 pesos por año, y es un hecho que se los pagaron, o al menos llegaron a algún acuerdo, ya que en 1669 nos encontramos que se ordenaba el pago de salario a Páez por los años de 1667 y 1668 , lo cual quiere decir que los años anteriores habían quedado saldados, y aún más, se trató en adelante de ir al corriente con dicho pago salarial. ${ }^{23}$

Esa solvencia económica coincide con la orden emitida por la Real Audiencia de Guadalajara en 1666, que con base en la resolución del Consejo de Indias de 1657, se favorecía al clero secular en general para controlar todo lo referente a los diezmos que cobraban las órdenes religiosas, prohibiéndole a éstas seguirlo haciendo en adelante, aplicando entonces tal sentencia al obispado de Guadalajara. Se obligó incluso a tales órdenes entregar a la mayordomía de Catedral lo cobrado desde 1657. ${ }^{24}$ Es claro que Juan de Páez desempeñó un papel fundamental en esta situación coyuntural.

\section{Juan de Páez ante su eficiencia demostrada}

No tenemos duda de que Juan de Páez actuó de manera eficiente y eficaz como mayordomo, mostrando ampliamente sus habilidades en el manejo de dinero. Imaginen qué impacto habrá tenido esa eficiencia, que más allá de la institución catedralicia, varios clérigos confiaron en él como su albacea testamentario, es decir, vieron en él a la persona idónea para manejar sus bienes post mortem. Fueron nueve los clérigos que dejaron a Juan de Páez como albacea testamentario durante el periodo en que fue mayordomo de la Catedral, esto sin contar los anteriores que hemos nombrado.

Como bien dice Thomas Calvo, Páez "hoy en día sería llamado experto financiero" (Calvo, 1989: 167), pues manejaba las cuentas de la Iglesia tapatía, las de los clérigos antes enlistados, las suyas propias y las de otros tantos más. En el caso de la mayordomía, habrá que precisar que es muy probable que el mérito del buen manejo de las finanzas eclesiásticas lo compartió con su

23. Ibídem; ff. 135f. y 147v.-148f.

24. Ibídem; f. $128 f$. 
compadre y amigo, el clérigo Francisco de Quijada, quien casi durante todos los 20 años en que Páez fue mayordomo, él hizo lo propio como contador, y recordemos que la administración de las rentas decimales la componían: jueces hacedores, mayordomo y contador.

El contador era quien cuadraba los movimientos ejercidos por el mayordomo, y quien en teoría debía informar al Cabildo lo procedido en tales asuntos. Tenemos entonces que Juan de Páez dependía en gran medida del trabajo contable que hiciera Quijada, y por su parte éste dependía de que Páez hiciera un trabajo ordenado y eficiente. Sin duda, así fue. Por ello, al morir el japonés, Francisco Quijada quedó como mayordomo, pues ésa era la decisión más práctica.

\section{El clan Páez después de la muerte de su patriarca}

Juan de Páez falleció a los 69 años de edad, el 15 de diciembre de 1675, y a petición expresa, con aprobación del Cabildo Eclesiástico de Guadalajara, se enterró al pie del Altar del Santo Cristo que estaba en la nave lateral izquierda, entre la quinta y sexta columnas del templo. Le sobrevivieron su esposa Margarita y cuatro hijas: María, Juana, Francisca y Margarita.

Es en su último testamento cuando Juan de Páez declara su origen nipón, señalando que era oriundo de Osaka. Como hombre rico que fue, dejó en primera instancia seis mil pesos en reales para que se impusieran en "fincas ciertas y seguras" con el objeto de fundar una capellanía. Dejó además mil pesos en reales para que se invirtieran sobre "fincas seguras" y cuya renta se destinase a la Iglesia para los gastos de cera, vino y vestuario del Altar del Santo Cristo.

Páez testó ante el escribano público Thomas de Orendain, ante quien designó como albaceas a su mujer y a sus amigos miembros de la Iglesia: el licenciado Simón Conejero Ruiz, racionero de la Catedral, y al licenciado Francisco de Quijada, clérigo presbítero, secretario del Cabildo, contador de las rentas decimales y sucesor de Juan de Páez en la mayordomía de Catedral. Páez dejó finalmente como tenedores de sus bienes o "de lo que resultase de su venta", a su esposa y a Francisco de Quijada.

Margarita sobrevivió a su marido y se convirtió en la matriarca de la familia, como nos lo revela el padrón de feligreses que levantó la parroquia de la Catedral en 1679. De acuerdo con éste, la familia ampliada de Margarita de Encío estaba integrada por 25 personas entre familiares, esclavos y sirvientes, la mayoría mujeres. Entre los familiares se mencionan en dicho padrón a dos 
hijas: Juana y Margarita, también el viudo de Francisca, Milián de Galarza, y la nieta Rosa Sánchez. Diecisiete esclavos aparecen al servicio de los Páez: cinco negras, 11 mulatas y Juan de Dios, del que no sabemos su origen racial. Una india de nombre María completa el séquito de servicio. Juan de Páez llegó a tener una fuerte suma invertida en esclavos, pues en los registros consultados encontramos un total de 27 esclavos atribuidos al japonés..$^{25}$ En Guadalajara predominaban las esclavas negras y mulatas en comparación con los esclavos hombres; la mayoría de aquéllas estaban involucradas en labores domésticas al servicio de la élite tapatía.

Margarita de Encío murió un año después de levantado ese padrón parroquial y fue enterrada, al igual que su marido, en la Catedral. Su hija Juana tomó entonces las riendas del clan por casi tres décadas más. Juana falleció en 1704 habiendo nombrado albacea de sus bienes a su cuñado Milián de Galarza y favoreció al santuario de Nuestra Señora de la Soledad con una de las casas de su propiedad ubicada sobre la calle de San Agustín. Le sobrevivieron a ella sus cuatro hijos y siete sobrinos. ¿Qué paso con ellos? Es motivo de otra investigación.

\section{Hallazgos y tareas pendientes}

De inicio, la gran incógnita en esta investigación era (y lo sigue siendo, pero con más pistas para seguir avanzando): ¿cómo pudieron haber llegado japoneses a la Guadalajara del siglo XVII? En la búsqueda de la respuesta pudimos al menos delimitar algunas hipótesis, las cuales están enteramente relacionadas con la historia de los primeros contactos hispano-japoneses, y en los cuales la Nueva España (hoy México) ejerció un papel protagónico. Una historia en la que hay envuelta una conjugación de sucesos donde intervino el interés de los gobernantes japoneses por comerciar con los europeos, mientras que los españoles tenían un fuerte interés por evangelizar a los habitantes del archipiélago nipón, y donde vemos a los jesuitas haciendo un importante recorrido misionero en esos lares (apoyados en un primer momento por la Corona portuguesa). Súmense además los hechos coyunturales de la historia

25. Thomas Calvo (1992: 146) nos informa que en la Guadalajara del siglo XVII, a partir de 1630 es cuando se empezaron a introducir de forma importante esclavos traídos de África por medio de mercaderes locales vinculados con portugueses de la ciudad de México, la mayoría provenientes de Angola. 
de aquel país, que nos ayudan a comprender mejor por qué miles de japoneses salieron de ahí en esos años: hablamos de la Batalla de Sekigahara (1600), las políticas anticristianas de Tokugawa (1612) y la toma de Osaka (1615), lugar donde habitaba una numerosa cantidad de japoneses conversos al cristianismo, influenciados por una de las misiones jesuitas ahí establecida.

Las hipótesis resultantes, puestas en orden cronológico, son las siguientes: a) el regreso de Rodrigo de Vivero y Velasco, de Japón a la Nueva España en 1610; b) el regreso de Sebastián Vizcaíno y la Misión Hasekura, que arribó a la Nueva España en 1614; c) el viaje de regreso de fray Diego de Santa Catalina, quien protagonizó la última embajada española en Japón en aquella época (1617). En estos tres viajes transpacíficos venían a bordo decenas de japoneses, ya fuera como tripulantes o como pasajeros; d) finalmente, los viajes del Galeón de Manila a la Nueva España ofrecen otra posibilidad, ya que en Manila existía una colonia numerosa de japoneses y consideramos probable que algunos de ellos viajaron en la Nao de China y ya no hicieron el viaje de regreso, teniendo en cuenta que los galeones que iban de Manila a Acapulco, y viceversa, hacían un viaje por año.

Sobre Encío, sabemos gracias a Eikichi Hayashiya que su apellido japonés era Fukuchi, que quizá fue samurai, y que quizá era oriundo del norte de Honshu (isla principal de Japón). Sospechamos que sus primeros años en la Nueva España los pasó en el pueblo de Ahuacatlán, lugar donde probablemente se casó con Catalina de Silva, y donde nació su hija, Margarita de Encío, quien fuera la esposa de Juan de Páez. De lo que hay más certeza es que Encío y su familia se establecieron en Guadalajara para el año de 1634, o al menos cerca de ese año, mismo por el que la familia Encío debió haber conocido y emparentado con Juan de Páez. Así, hablar de Juan de Páez nos lleva sin falta a hablar de Luis de Encío y viceversa, pues simplemente los descendientes de Páez lo son también de Encío.

Sobre cómo y cuándo llegó Juan de Páez a Guadalajara, de acuerdo con las fuentes consultadas deducimos - aunque sin poderlo comprobar aún-que este japonés llegó alrededor del año 1618, siendo un niño de aproximadamente 10 años de edad. Al no encontrar señal alguna de padres, tutor o padrinos, pero sabiendo en dónde nació, imaginamos la posibilidad de que era un huérfano cobijado por los jesuitas expulsados de Japón y que trajeron a ese niño con ellos. También creemos que precisamente los jesuitas fueron los encargados de darle esa educación que lo ayudaría a sobresalir en el ambiente económico y social de la Nueva Galicia. Pero esto aún no lo hemos podido comprobar, por 
lo cual no descartamos que esa misma protección y educación las recibiera de alguna otra orden religiosa que haya tenido misioneros en Japón, como sería el caso de los franciscanos. De lo que sí tenemos total certeza, gracias al propio Juan de Páez, es que éste nació en la ciudad portuaria de Osaka.

Creemos poco probable que Páez haya llegado a través del viaje de regreso de Rodrigo de Vivero y Velasco (1610), al igual que en la Misión Hasekura (1614); nos parece más factible la posibilidad de que haya llegado en el viaje de regreso de fray Diego de Santa Catalina (1617); pero aún más probable vemos a la ruta vía Manila, siendo esta ciudad destino de primera mano para los católicos expulsados de Japón, sobre todo a partir de 1614, así como de aquéllos desplazados por los acontecimientos bélicos de Osaka en 1615.

Para seguir armando la cronología biográfica de Páez, nos fue de mucha ayuda el haber encontrado el registro de bautismo de su primer hijo, del año 1637, dato que combinándolo con otros disponibles, nos permitió lograr algunos acercamientos sobre aspectos como: cuándo se unió en matrimonio con Margarita de Encío (1635 ó 1636), reafirmar su posible edad infantil al arribar a Guadalajara, entre otros detalles.

Precisamente sobre su familia tapatía, sabemos que Juan de Páez y su esposa Margarita de Encío tuvieron nueve hijos, de quienes sólo siete llegaron a edad adulta, y de esos siete, sólo dos (María y Juana) pasaron de los 30 años de edad; a pesar de ello, fueron 13 los nietos que tuvo Juan de Páez, aunque varios de ellos nacieron después de 1675, año en que murió el oriundo de Osaka.

Como en todo personaje del pasado, no conviene idealizarlo, y teniendo en cuenta entonces que Juan de Páez era un hombre de su época, nos encontramos que fue uno de los principales propietarios de esclavos -en su caso esclavas - en Guadalajara, así como activo gestor de terceros en la compraventa practicada en ese tipo de comercio (legal en aquel entonces).

Juan de Páez murió en 1675, fue sepultado al pie del Altar del Santo Cristo de la Catedral. El patriarcado que él representaba se convirtió entonces en un matriarcado, al quedar como cabeza del clan Páez-Encío, Margarita de Encío acompañada en cuanto a la administración de los bienes dejados por su marido, por el padre Francisco de Quijada, hombre de todas las confianzas de Juan de Páez y de toda su familia. Margarita de Encío murió cinco años después que su esposo, continuando la línea matriarcal bajo el mando de Juana de Páez, quien al parecer heredó los talentos de su padre. 
En lo que a la vida pública o laboral se refiere, Juan de Páez alcanzó un alto nivel de eficiencia y eficacia en su desempeño, aspectos reconocidos por la sociedad en que se desarrolló, y siendo las mejores pruebas de ello el hecho de que su nombre sea el que más se repite como albacea testamentario en la registros de entierro de la ciudad entre 1634 y 1674, también el haber sido corregidor de Zapopan, así como mayordomo de Catedral; siendo quizá esto último lo que le dio mayor relevancia en la Guadalajara de su tiempo, y lo que le da relevancia en el estudio actual de la historia colonial de esta ciudad.

Fue mayordomo de Catedral (co-encargado de la administración de las rentas decimales del obispado de Guadalajara) a partir del año 1654, manteniéndose como tal hasta su último día de vida, convirtiéndose en el hombre de todas las confianzas del clero tapatío, ello gracias a su buen desempeño como hombre de negocios. Sobre Juan de Páez, en general, no vacilamos en proponerlo como un personaje sobresaliente para la historia económica de la Guadalajara del siglo XVII, y quizá quedándonos cortos en la afirmación, sabiendo que sus negocios llegaban hasta la capital novohispana.

Tenemos así que el papel tan importante que desempeñó este japonéstapatío en la sociedad y en la economía de una Guadalajara en proceso de consolidación, muestra por una parte a una sociedad flexible que sabe reconocer el genio emprendedor sin importar el origen racial, y por otra, la capacidad del japonés para ascender a la cúpula de esa sociedad e incorporarse a ella sin más armas que las de su propia educación. Sin duda ésta es una muestra de que la inmigración es una fuente de energía creativa de la que se benefician las sociedades receptoras.

Finalmente, esperamos que los hallazgos de esta investigación puedan ser utilizados por otros estudiosos del tema para completar la historia de Juan de Páez y Luis de Encío. Además, ojalá esta historia sirva como una contribución, aunque sea pequeña, en el conocimiento sobre las primeras relaciones entre la Nueva España y Japón, así como el papel que tuvo en éstas la Nueva Galicia, y cómo influenció todo ello en la Guadalajara del siglo XVII. આู̣

\section{Acervos documentales consultados}

Archivos

Archivo del Cabildo Eclesiástico de Guadalajara (ACEG). Archivo Histórico del Arzobispado de Guadalajara (AHAG). 
Archivo Histórico del Estado de Jalisco (AHEJ).

Archivo de Instrumentos Públicos del Estado de Jalisco (AIPJ).

Archivo del Sagrario Metropolitano de Guadalajara (ASMG).

Biblioteca Pública del Estado de Jalisco "Juan José Arreola": Archivo de la Real Audiencia de Guadalajara (ARAG).

\section{Bibliotecas}

Biblioteca del Archivo Histórico del Estado de Jalisco.

Biblioteca del Departamento de Estudios del Pacífico (DEP) (Universidad de Guadalajara).

Biblioteca Digital del Instituto Tecnológico de Estudios Superiores de Monterrey (ITESM), Campus Guadalajara; Base de datos: JSTOR.

Biblioteca “Dr. Jorge Villalobos Padilla, S. J.", Instituto Tecnológico de Estudios Superiores de Occidente (ITESO).

Biblioteca "W. Michel Mathes", El Colegio de Jalisco.

Centro de Información y Comunicación "Dr. Manuel Rodríguez Lapuente" [Biblioteca Central del] Centro Universitario de Ciencias Sociales y Humanidades (CUCSH) de la Universidad de Guadalajara.

Hemeroteca Digital: Red de Revistas Científicas de América Latina, el Caribe, España y Portugal (Redalyc): http://redalyc.uaemex.mx; Universidad Autónoma del Estado de México.

\section{Referencias bibliográficas}

Arcos, María Fernanda G. de los (2002), “The Philippine Colonial Elite and the Evangelization of Japan", Bulletin of Portuguese/Japanese Studies, núm. 4, pp. 63-89.

Barrón Soto, Ma. Cristina E. (1990), "Aceptación y resistencia a los valores hispánicos en la Nueva España, Filipinas y Japón”, en Ma. Cristina Barrón y Rafael Rodríguez-Ponga (coord.), La presencia novohispana en el Pacífico insular, Actas de las Primeras Jornadas Internacionales celebradas en la ciudad de México, del 19 al 21 de septiembre de 1989, México, DF: Universidad Iberoamericana/Embajada de España en México/Comisión Puebla V Centenario/Pinoteca Virreinal, pp. 139-156.

Barrón Soto, Ma. Cristina E., y Rafael Rodríguez-Ponga (coord.) (1990), La presencia novohispana en el Pacífico insular, Actas de las Primeras Jornadas 
Internacionales celebradas en la ciudad de México, del 19 al 21 de septiembre de 1989, México, DF: Universidad Iberoamericana/Embajada de España en México/Comisión Puebla V Centenario/Pinoteca Virreinal, p. 209.

Borah, Woodrow (1986), "La recolección de diezmos en el obispado de Oaxaca", en A. J. Bauer (comp.), La Iglesia en la economía de América Latina, siglos XVI al XIX, México, DF: Instituto Nacional de Antropología e Historia, pp. 61-100.

Borao, José Eugenio (2005), "La colonia de japoneses en Manila en el marco de las relaciones de Filipinas y Japón en los siglos XVI y XVII", Cuadernos Canela: Actas de la Confederación Académica Nipona, Española y Latinoamericana, vol. XVII. Disponible en: http://www.canela.org.es

Boscaro, Adriana (1973), Sixteenth Century European Printed Works on the First Japanese Mission to Europe: A descriptive bibliography, Leiden, Países Bajos: E. J. Brill; pp. VII-XIX, 102-105, 110-111, 148-149, 172-196.

Boxer, C. R. (1951), The Christian Century in Japan 1549-1650, Berkeley: University of California Press, p. 535.

Brown, Judith C. (1994), "Courtiers and Christians: The First Japanese Emissaries to Europe”, Renaissance Quarterly, 47(4), invierno, pp. 872-906.

Calderón, Francisco R. (1988), Historia económica de la Nueva España en tiempos de los Austrias, México, DF: Fondo de Cultura Económica, pp. 95-140, 152-166, 183-190, 563-579.

Calvo, Thomas (1989), “Japoneses en Guadalajara: 'Blancos de Honor' durante el Seiscientos mexicano", en Thomas Calvo, La Nueva Galicia en los siglos XVI y XVII, Guadalajara: El Colegio de Jalisco/Centro de Estudios Mexicanos y Centroamericanos, pp. 159-171.

_- (1991), Poder, religión y sociedad en la Guadalajara del siglo XVII, Guadalajara: Centre d'Etudes Mexicaines et Centraméricaines/H. Ayuntamiento de Guadalajara, p. 423.

- - (1992), Guadalajara y su región en el siglo XVII: Población y economía, Guadalajara: Centro de Estudios Mexicanos y Centroamericanos/H. Ayuntamiento de Guadalajara, p. 489.

Castañeda, Carmen (1984), La educación en Guadalajara durante la Colonia, 1552-1821, Guadalajara: El Colegio de Jalisco/El Colegio de México, pp. 41-87.

Chávez Hayhoe, Arturo (1953), Guadalajara en el siglo XVI, tomo primero, Guadalajara: Banco Refaccionario de Jalisco, pp. 221-246. 
(1954), Guadalajara en el siglo XVI, tomo segundo, Guadalajara: Banco Refaccionario de Jalisco, p. 259.

Chie, Nakane (1990), “Tokugawa Society”, en Chie Nakane y Shinzaburō Öishi (ed.), Tokugawa Japan. The Social and Economic Antecedents of Modern Japan, Tokio: University of Tokyo Press.

Fernández, Rodolfo (1991), "Esclavos de ascendencia negra en Guadalajara en los siglos XVII y XVIII", Estudios de Historia Novohispana, vol. II, junio, pp. 71-84.

Florencia, Francisco de (1998 [1757]), Origen de los dos célebres santuarios de la Nueva Galicia [edición facsimilar], Zapopan: El Colegio de Jalisco, pp. 20, 21, 45 y 46.

Hayashiya, Eikichi (2003), "Los japoneses que se quedaron en México en el siglo XVII. Acerca de un samurai en Guadalajara", México y la Cuenca del Pacífico, 6(18), pp. 10-17.

Híjar Ornelas, Tomás de, y Verónica Bertha Cortés Alba (2007), La parroquia y la comarca zapopana en el siglo XVII, Guadalajara: Instituto Cultural Ignacio Dávila Garibi, A. C./Cámara de Comercio de Guadalajara, p. 38.

Iguíniz, Juan B. (comp.) (1950), Guadalajara a través de los tiempos: Relatos $y$ descripciones de viajeros y escritores desde el siglo XVI hasta nuestros días, tomo I, 1586-1867, Guadalajara: Banco Refaccionario de Jalisco.

Iranzo, V. Sebastián (1991), "Diezmos y primicias en la historia eclesiástica", Enciclopedia GER [Edición Web], Madrid: Ediciones Rialp/Canal Social, Montané Comunicación. Disponible en: http://www.canalsocial.net/ger/ ficha_ger.asp?id=8975\&cat=historiaiglesia

Kaibara, Yukio (2000), Historia del Japón, México, DF: Fondo de Cultura Económica, pp. 139-191.

Knauth, Lothar (1972), Confrontación transpacífica: El Japón y el nuevo mundo hispánico: 1542-1639, México, DF: UNAM-Instituto de Investigaciones Históricas, p. 423.

Lavrin, Asunción (1991), "Perfil histórico de la población negra, esclava y libre (1635-1699)", en José María Muría y Jaime Olveda (comp.), Lecturas históricas de Guadalajara II: Sociedad y costumbres, México, DF: INAH/ Gobierno del Estado de Jalisco/Universidad de Guadalajara, pp. 35-46.

León Portilla, Miguel (1992), "La embajada de los japoneses en México: El testimonio en náhuatl del cronista Chimalpahin", en Javier Wimer (coord.), El Galeón del Pacífico, Acapulco-Manila 1565-1815, México, DF: Gobierno del Estado de Guerrero-Instituto Guerrerense de Cultura, pp. 137-151. 
López Moreno, Eduardo (2002), La cuadrícula en el desarrollo de la ciudad hispanoamericana, Guadalajara, México, Guadalajara: Universidad de Guadalajara-Centro Universitario de Arte, Arquitectura y Diseño/Instituto Tecnológico y de Estudios Superiores de Occidente, p. 230.

Martínez González, Héctor Antonio (1992), La Catedral de Guadalajara, Guadalajara: Amate.

Mathes, W. Michel (1973), Sebastián Vizcaíno y la expansión hispánica en el Océano Pacífico, México, DF: UNAM-Instituto de Investigaciones Históricas, Ignacio del Río (traductor), p. 145.

- - (2006), "A Quarter Century of Trans-Pacific Diplomacy: New Spain and Japan, 1592-1617”, en Mark Caprio y Matsuda Koichiro (ed.), Japan and the Pacific, 1540-1920, Aldershot, Gran Bretaña: Ashgate/Variorum, pp. 57-86 [1-29].

Miranda, Roberto (2002), ¿Esclavos aquí? Notas para el estudio de la esclavitud en la Nueva Galicia, Guadalajara: Universidad de Guadalajara-Centro de Investigaciones del Departamento de Ciencias Sociales y Jurídicas, pp. 15-25.

Molina, Antonio M. (1992), América en Filipinas, Madrid: MAPFRE, pp. 21-41, 94-108, 278-287.

Muriá, José María, Jaime Olveda, y Mario Aldana Rendón (2004), Historia de Zapopan, Zapopan: El Colegio de Jalisco/Ayuntamiento Constitucional de Zapopan, pp. 21-41.

Núñez Ortega, Ángel (1971 [1923]), Noticia histórica de las relaciones políticas y comerciales entre México y el Japón durante el siglo XVII, $2^{\mathrm{a}}$ edición, México, DF: Porrúa, pp. 46-53, 73-77, 86-87, 94-97, 104-127.

Oliveira E Costa, João Paulo (2003), “Tokugawa Ieyasu and the Christian daimyō during the crisis of 1600", Bulletin of Portuguese/Japanese Studies, núm. 7, pp. 45-71.

Olveda, Jaime (1995), "El Puerto de La Navidad: Perlas, comercio y filipinos", en Jaime Olveda (coord.), III Coloquio La Cuenca Hispana del Pacífico: Pasado y Futuro, Guadalajara: Sociedad de Geografía y Estadística del Estado de Jalisco, pp. 61-80.

Ota Mishima, María Elena (1990), "La misión Hasekura, un intento de firma de un convenio de comercio con México, en la época colonial, 1610-1620", en Ma. Cristina Barrón y Rafael Rodríguez-Ponga (coord.), La presencia novohispana en el Pacífico insular, Actas de las Primeras Jornadas Internacionales celebradas en la ciudad de México, del 19 al 21 de septiembre de 1989, 
México, DF: Universidad Iberoamericana/Embajada de España en México/ Comisión Puebla V Centenario/Pinoteca Virreinal, pp. 195-205.

Palacio y Basave, Luis del Refugio (1904), La Catedral de Guadalajara, Guadalajara: Artes Gráficos (1948: reimpresión en conmemoración del IV centenario de la fundación del Obispado de Guadalajara), pp. 67-76.

Palomera, Esteban J. (1986), La obra educativa de los jesuitas en Guadalajara, 1586-1986, Guadalajara: Instituto de Ciencias (Guadalajara)/Universidad Iberoamericana-Departamento de Historia, pp. 38-65.

Palomino y Cañedo, Jorge (1972), Los protocolos de Rodrigo Hernández Cordero, 1585-1591, escribano público de Guadalajara, Guadalajara: Ediciones del Banco Industrial de Jalisco, pp. 161, 268-269.

Pérez Puente, Leticia (2001), "Dos periodos de conflicto en torno a la administración del diezmo en el Arzobispado de México: 1653-1663 y 16641680", Estudios de Historia Novohispana, núm. 25, pp. 15-57.

Ribeiro, Madalena (2001), "The Japanese Diaspora in the Seventeenth Century. According to Jesuit Sources", Bulletin of Portuguese/Japanese Studies, núm. 3, pp. 53-83.

Schütte, Josef Franz (1980), “Don Rodrigo de Vivero de Velazco y Sebastián Vizcaíno en Japón (1609-1610, 1611-1613)”, en Ernesto de la Torre Villar (comp.), La expansión hispanoamericana en Asia, siglos XVI y XVII, México, DF: Fondo de Cultura Económica, pp. 96-122.

Schwade, Arcadio (1980), "Las primeras relaciones entre Japón y México (1609-1616)", en Ernesto de la Torre Villar (comp.), La expansión hispanoamericana en Asia, siglos XVI y XVII, México, DF: Fondo de Cultura Económica, pp. 123-133.

Shinzaburo, Oishi (1990), “The Bakuhan System”, en Chie Nakane y Shinzaburō Öishi (ed.), Tokugawa Japan. The Social and Economic Antecedents of Modern Japan, Tokio: University of Tokyo Press.

Takahiro, Nakamae (1990), "Los primeros contactos del Japón con Nueva España”, en Ma. Cristina Barrón y Rafael Rodríguez-Ponga (coords.), La presencia novohispana en el Pacífico insular, Actas de las Primeras Jornadas Internacionales celebradas en la ciudad de México, del 19 al 21 de septiembre de 1989, México, DF: Universidad Iberoamericana/Embajada de España en México/Comisión Puebla V Centenario/Pinoteca Virreinal, pp. 187-193. Torre Villar, Ernesto de la (comp.) (1980), La expansión hispanoamericana en Asia, siglos XVI y XVII, México, DF: Fondo de Cultura Económica, p. 167. 
Valencia Japón, Víctor (s/f), "De Japón a Roma pasando por Coria, 16141620", Sitio [Web] Oficial del Ayuntamiento de Coria del Río. Disponible en: http://www.coriadelrio.es/opencms/opencms/coria/municipio/Historia/ aportaciones/hasekura.html

Vizcarra de Jiménez, Eugenia Irma, y Miguel Claudio Jiménez y Vizcarra (1981), Noticias biográficas contenidas en las partidas de entierro de los libros segundo, tercero y cuarto de defunciones del Archivo del Sagrario Metropolitano de la ciudad de Guadalajara, 1634-1667, Guadalajara: Sociedad de Historia, Genealogía y Heráldica de Jalisco, A. C., p. 96. 
Melba Falck Reyes

Héctor Palacios

\section{El japonés que conquistó Guadalajara}

La historia de Juan de Páez

en la Guadalajara del siglo XVII

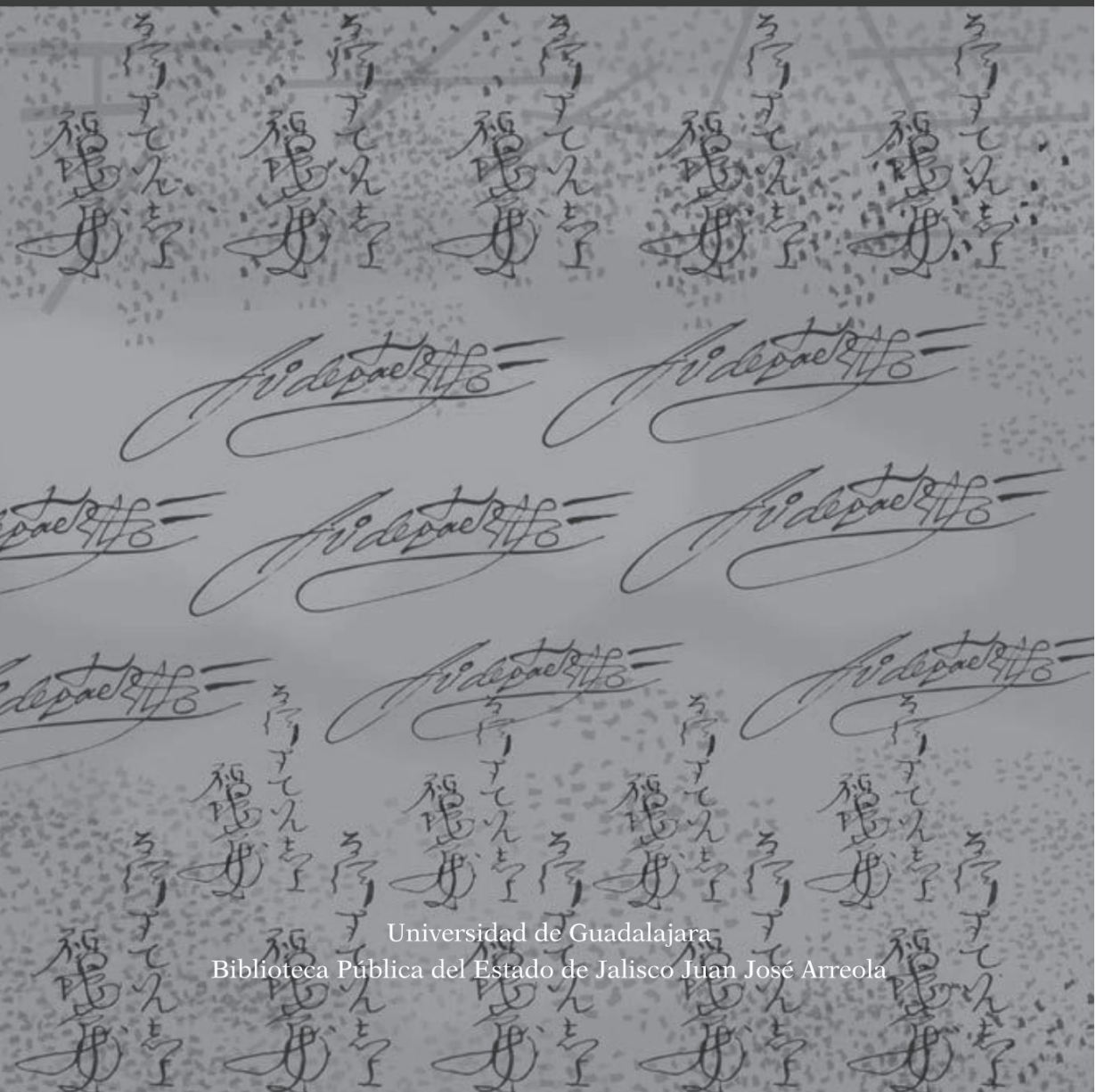

